\title{
¿QUÉ JUSTICIA QUEREMOS? ESENCIA Y EXISTENCIA DEL PODER JUDICIAL
}

\author{
JUAN DAMIÁN MORENO \\ Catedrático de Derecho Procesal \\ Universidad Autónoma de Madrid
}

\author{
SUMARIO \\ I. Introducción. El poder judicial al cabo de \\ 30 años de LOPJ. \\ II. Esencia y existencia del poder judicial. Po- \\ der judicial y potestad jurisdiccional. \\ III. El Consejo General del Poder Judicial: Sag- \\ gio polemico o enigma indescifrable. \\ IV. Independencia y responsabilidad judicial. \\ ¿En qué consiste ser un buen juez? \\ V. ¿Qué justicia queremos?
}

\section{INTRODUCCIÓN. EL PODER JUDICIAL AL CABO DE 30 AÑOS DE LOPJ}

Como acertadamente tuvo ocasión de poner de relieve Díez-Picazo, si bien la Constitución no proclama de manera explícita el reconocimiento del principio de división de poderes, su existencia se desprende inequívocamente de todo su articulado ${ }^{1}$. Por eso la aprobación de la Constitución de 1978, y el cambio político que con la misma se lleva a cabo, determinó la inmediata necesidad de afrontar una reforma en profundidad de nuestra estructura judicial a partir del reconocimiento del poder judicial como un auténtico poder del Estado.

El 1 de julio de 1985 se promulgaba la Ley Orgánica del Poder Judicial. Han transcurrido treinta años desde su aprobación. La importancia de esta ley es in-

1 Díez-Picazo Giménez, L.: Régimen constitucional del poder judicial, Madrid, 1991, p. 19. 
cuestionable; dio cuerpo y contenido al poder judicial que acababa de nacer tras la Constitución de 1978. Reflejó no sólo el espíritu de su tiempo sino el ideario de las democracias más avanzadas en relación con el modelo de separación de poderes al que razonablemente habría de aspirar la sociedad española durante la transición ${ }^{2}$. No fue un mero desarrollo de la normativa que la Constitución dedica al poder judicial; fue, sobre todo, una opción de política legislativa de entre las varias alternativas que ofrecía el texto constitucional. Los cimientos estaban puestos pero había que replantear y acomodar el poder judicial a aquél nuevo escenario que aún en muchos aspectos conservaba los rasgos, el entramado interior y el espíritu de la legislación proveniente de finales del siglo XIX ${ }^{3}$. Y aunque no todas las reformas fueron acogidas con el mismo entusiasmo e, incluso, algunas treinta años después, siguen siendo objeto de intensos y acalorados debates, lo cierto es que hay que reconocerle a esta ley el gran mérito de haber puesto orden en la legislación existente hasta ese momento, de haber renovado en parte la planta judicial heredada del antiguo régimen y, en suma, de haber adecuado nuestro sistema judicial a las exigencias constitucionales.

La ley ha sufrido a lo largo de estos treinta años muchas modificaciones y algunas reformas, algunas de carácter puntual o anecdótico y otras de enorme trascendencia, y aunque al final, materias tan controvertidas tales como la designación de los vocales del Consejo General del Poder Judicial o la modificación del sistema de acceso a la carrera judicial acabaron siempre dando lugar a una solución de compromiso entre los dos partidos mayoritarios, en lo tocante al resto de las materias, la situación se ha ido manteniendo sustancialmente tal como fueron aprobadas. Entre ellas cabe resaltar la contenida en el Título Preliminar que, en opinión de uno de sus principales impulsores, Fernando Ledesma, era el verdadero corazón de la ley ${ }^{4}$, y que hoy en día sigue constituyendo un referente de gran trascendencia en el ámbito del ejercicio de la actividad jurisdiccional en la medida en que, como objetivo estratégico, trató de establecer las bases para que los jueces pudieran adaptar el ejercicio de la función judicial al nuevo orden constitucional.

De entre todas las reformas destaco la llevada a cabo por la Ley Orgánica 16/1994, de 8 de noviembre y por Ley 19/2003, de 23 de diciembre. La primera, y probablemente la más importante desde que se promulgó la Ley de 1985, tuvo un enorme valor simbólico ya que pretendió sentar los principios sobre los

2 Alzaga Villaamil, O.: Comentario sistemático a la Constitución Española de 1978, Madrid, 1978, p. 715 y Peces-Barba, G.: La elaboración de la Constitución de 1978, Madrid, 1988, p. 77.

3 Tomás y VALIENTE sostuvo en cambio que fue la Ley de 1870 la que realmente dibujó el modelo de judicatura para los años posteriores y que la ley promulgada en 1985 no lo sustituye por otro sino que lo completa y mejora [TOMÁs y VALIENTE, F.: «Independencia judicial y garantía de los derechos fundamentales», en Constitución: escritos de introducción histórica, en OBRAS COMPLETAS, Centro de Estudios Políticos y Constitucionales, Madrid, 1997, p. 2.590].

4 Ledesma Bartret, F.: «Cinco años y medio en el Ministerio de Justicia», en La Ley, 5, 2001, p. 1764. 
que avanzar hacia un verdadero equilibrio entre los poderes del Estado, lo cual se intentó mediante una ampliación de las competencias de Consejo General del Poder Judicial (al menos las que el gobierno de entonces consideró que debía tener para el íntegro ejercicio de sus funciones constitucionales). Con esta finalidad, y como instrumento necesario para el ejercicio de sus competencias, se le atribuyó la llamada potestad reglamentaria externa, que se configuró en principio de manera excepcional y siembre al objeto de desarrollar las materias que legalmente estaban establecidas, y le confirió la potestad de elaborar, dirigir y controlar los gastos en el marco de su pretendida autonomía presupuestaria. También acometió una modificación en profundidad del ejercicio de la potestad disciplinaria a fin de que ésta pudiera servir de instrumento indispensable para el adecuado funcionamiento de la administración de justicia y, al tiempo que procedió a una nueva tipificación de las actuaciones sancionables, dio una nueva regulación a la prescripción al objeto de evitar la impunidad de ciertas conductas. Así mismo, se introdujeron modificaciones en las pruebas de acceso a la carrera judicial por el tercer y cuarto turno, el régimen de los magistrados suplentes y jueces sustitutos, incorporando la figura del juez adjunto, y algunas otras dirigidas a la mejora del sistema judicial.

La Ley 19/2003, de 23 de diciembre, tuvo un marcado carácter estatutario, en la medida en que gran parte de su articulado tuvo por objeto regular aspectos que afectaban al complejo mundo de las relaciones que afectan a jueces y magistrados en su condición de funcionarios públicos, reforzó los criterios de profesionalización y especialización en el acceso y promoción de los miembros de la carrera judicial intentando que al frente de cada juzgado se encontraran jueces y magistrados con una preparación adecuada al desempeño sus funciones jurisdiccionales. Esta reforma tuvo además una importancia decisiva en el diseño de la nueva oficina judicial; hay que tener en cuenta que el modelo de oficina judicial que ha predominado en nuestro país ha sido, y en algunos casos sigue siendo, excesivamente personalista, heredero de una estructura organizativa propia del siglo XIX y, en consecuencia, muy alejada de las modernas técnicas de distribución del trabajo que tratan de obtener el máximo rendimiento de los recursos disponibles. Entre sus objetivos destaca el de haber establecido las bases para la reorganización de un modelo de oficina judicial integrada por unidades procesales de apoyo directo y servicios comunes, optando así por un sistema flexible que les permitiera ir adaptándose, en función de las posibilidades organizativas, técnicas y presupuestarias de cada comunidad autónoma, a un modelo más racional y eficiente.

Por último, hemos de mencionar por su importancia la reforma llevada a cabo por la Ley Orgánica 4/2014 mediante la que se procedió a incorporar a la LOPJ un nuevo Libro destinado a cobijar el enésimo intento de reformar el Consejo General del Poder Judicial. Como tendremos ocasión de exponer, esta modificación legal tuvo por objeto fundamental replantearse íntegramente la composición, las atribuciones y el sistema de elección de los vocales del órgano de gobierno del poder judicial en previsión a lo que, en principio, conformaría el Libro 
$I V$ de los siete que presumiblemente habría de contener la futura propuesta de Anteproyecto de Ley Orgánica del Poder Judicial, aunque en este último aspecto, no precisamente en la línea propuesta por la comisión nombrada al efecto por el Consejo de Ministros (BOE 13 de marzo de 2012).

En este sentido, no puedo dejar de mencionar que la propuesta que preparó la comisión encargada de elaborar un texto que sustituyera a la vigente ley se hizo cumpliendo escrupulosamente las directrices marcadas por el acuerdo del Consejo de Ministros aprobado con este fin y en el convencimiento de que, tras tantas reformas parciales, había llegado el momento de afrontar la modificación integral de una ley que, respetando en todo caso los avances alcanzados durante estos treinta años de vigencia de la promulgada en 1985, diera una renovada respuesta a las futuras necesidades de la justicia, un periodo intenso y que muestra, más allá del debate académico, lo que para unos y para otros representa el poder judicial en una sociedad democrática.

Al momento de terminar de redactar estas líneas acaba de aprobarse una nueva reforma de la Ley Orgánica del Poder Judicial (Ley Orgánica 7/2015, de 21 de julio). El texto aborda una serie de medidas tendentes mejorar el funcionamiento de la justicia mediante una distribución más racional de carga de trabajo entre los distintos juzgados y tribunales sin tener que modificar la planta y demarcación judicial. También acoge el cambio de denominación del Cuerpo de Secretarios Judiciales, que pasan a llamarse Letrados de la Administración de Justi$\mathrm{cia}$. Entre las novedades que incorpora se encuentra, además, aquélla que incrementa en dos miembros más la composición de la Comisión Permanente del Consejo General del Poder Judicial, cuestión a la que aludiremos más adelante y que quizá es a la que se le ha dado mayor importancia; otra es la que permite a los magistrados que lo soliciten a prolongar su periodo de permanencia en activo hasta a los 72 años y se sientan las bases para acabar con la figura del magistrado emérito. La otra se refiere al recurso de casación en el ámbito de lo contencioso-administrativo, algo que dará que hablar porque no ha dejado de hacerlo antes incluso de su aprobación. Esta medida, que no entrará en vigor hasta dentro de un año, tiene por objeto reducir las tasas de litigiosidad mediante un reforzamiento de la jurisprudencia para lo cual se introduce como novedad la noción de interés casacional objetivo como elemento que permitirá el acceso a la casación. En el fondo no es más que ampliar el ámbito de la casación a través de la supresión del umbral cuantitativo que se encuentra actualmente establecido para dar entrada en el pro-

5 Aunque tal vez pudiera sorprender la forma en que se introdujo la reforma, existían poderosas razones que justificaron esta forma de proceder; en primer término, sortear un inconveniente de carácter técnico, ya que el texto que se elaboró a partir de la propuesta que preparó la comisión designada a tal efecto era mucho más reducido en número de artículos y por lo tanto insuficientes como para cubrir el hueco que dejaba la parte de la Ley que se derogaba, lo que hubiera obligado a reenumerar toda la Ley, y, en segundo lugar por coherencia con la propia Constitución que, como se dirá seguidamente, impone que sea la Ley Orgánica del Poder Judicial la que regule las materias referidas al Consejo General del Poder Judicial (art. 122). 
ceso contencioso-administrativo a una suerte de «certiorari» un poco más estandarizado en cuanto a los motivos que dan acceso a este recurso; de manera que será el propio Tribunal Supremo, quien a la vista de los criterios legales sea el que decida si un recurso merece o no la atención de ser considerado por el tribunal («certworthy») y, por lo tanto, quien en función de ellos, tanto en los casos en que el interés se presume como en los que no se presume, sea, como en los versos de Nicolás Guillén, quien abra o cierre la muralla de la casación ${ }^{6}$.

\section{ESENCIA Y EXISTENCIA DEL PODER JUDICIAL. PODER JUDICIAL Y POTESTAD JURISDICCIONAL}

Como nos recuerda un prestigioso filósofo contemporáneo, preguntarse por la esencia del poder significa saber qué es eso en lo que consiste realmente. Si tuviéramos que asignar la categoría de poder a la actividad que desarrollan los jueces no habría ninguna duda al afirmar que forman parte de un poder del Estado y en que su esencia consiste precisamente en administrar justicia decidiendo de forma irrevocable y definitiva las controversias que se les sometan de acuerdo a la ley. Así pues, es fácil advertir que constituye la esencia del poder judicial en sentido amplio el ejercicio atribuido a jueces y magistrados de la función de juzgar, una función que originariamente se encuentra su justificación en la necesidad de asegurar la pacífica convivencia entre los particulares, evitando que nadie pueda tomarse la justicia por su mano mediante la puesta a disposición de los ciudadanos de todo un sistema que les permita obtener una respuesta justa a sus pretensiones. Si no existiera el proceso ni la jurisdicción, y si el Estado a través de la sentencia del juez no fuera capaz de resolver definitivamente la controversia, el estado de conflictividad que dio origen al proceso nunca podría ser eliminado ${ }^{7}$.

Este efecto tan singular de las decisiones judiciales constituye un atributo específico y singular de la actividad jurisdiccional y con frecuencia es utilizado como criterio distintivo para diferenciar la esencia de la actividad jurisdiccional del resto de las actividades que llevan a cabo los tribunales, hasta tal punto

6 Procesalmente hablando, muy significativa también es la previsión que permitirá, a través del recurso de revisión, atribuir efecto revocatorio directo a las sentencias del Tribunal Europeo de Derecho Humanos. En esta misma dirección, se incluye la obligatoriedad de los jueces de aplicar el Derecho de la UE de conformidad con la jurisprudencia del TJCE. Entre las modificaciones que también incorpora, una de ellas afecta a las reglas reguladoras de la competencia judicial internacional; otra es la que hace desaparecer la responsabilidad civil directa de los jueces y magistrados; otra es la que en el ámbito de la oficina judicial regula todo lo atinente a la protección de datos de carácter personal en la administración de justicia y se establecen medidas para proceder la eliminación del papel acumulado en los juzgados mediante el expurgo de los expedientes de más de seis años de antigüedad desde la firmeza de la sentencia.

7 Monteleone, G.: «Note sui rapporti tra giurisdizione e legge nello Stato di Diritto», en Rivista trimestrale di diritto e procedura civile, $\mathrm{n} .{ }^{\circ} 1,1987, \mathrm{p}$. 5 . Por eso la gran parte de la doctrina ha considerado a la cosa juzgada como el atributo específico de la actividad jurisdiccional [RAMOs MÉNDEZ, F.: Derecho y proceso, Barcelona, 1979, p. 1381. 
que el gran procesalista uruguayo Eduardo J. Couture llegó incluso a afirmar que donde no había cosa juzgada no había actividad jurisdiccional propiamente dicha ${ }^{8}$.

Pero una cosa es la esencia del poder y otra muy diferente su existencia. Como sabemos, el poder judicial existe como tal desde el advenimiento del Estado moderno, estructurado bajo el dogma de la división de poderes ${ }^{9}$. Considerar como existente al poder judicial sólo puede explicarse en la medida en que consideremos que coexiste igualmente una estructura dentro del Estado a quien se le atribuye la potestad jurisdiccional. El hecho de que el ejercicio de la potestad jurisdiccional se encuentre confiado al poder judicial no es más que una de las notas características de nuestro modelo de Constitución basado en el principio de separación de poderes, pero no es inimaginable que puedan existir países donde el ejercicio de la potestad jurisdiccional no se encuentre atribuido al poder judicial. Poder judicial y potestad jurisdiccional no son términos idénticos; la potestad jurisdiccional implica y designa el ejercicio de una función; el poder judicial el órgano a quien se la encomienda ${ }^{10}$.

Así pues, cuando la Constitución proclama con toda solemnidad que la justicia emana del pueblo y se administra en nombre del Rey por jueces y magistrados integrantes del poder judicial, independientes, inamovibles, responsables y sometidos únicamente al imperio de la ley, pareciese como que lo que nos está diciendo son varias cosas de enorme relevancia: (i) que los españoles en el ejercicio de su soberanía han decidido encomendar esta función o, si se quiere, esta forma tan característica de resolución de controversias a jueces y magistrados que integran una estructura o un aparato al margen del resto de las actividades de gestión que pudiera atribuir a otros poderes públicos; y (ii) que para llevar a cabo esa función, con independencia respecto de los demás poderes del Estado, les han dotado de una serie de garantías específicas para que puedan asumir esta labor sin interferencias, condicionando en todo caso el ejercicio de esta actividad al cumplimiento de la ley ${ }^{11}$.

La idea es que el poder judicial, como encarnación de la jurisdicción, actúe asegurando la actuación del derecho objetivo en el marco del Estado de Derecho,

8 Couture, E.: Fundamentos de derecho procesal civil, Buenos Aires, 1978, p. 43. Por lo tanto, no es que aquella característica, como sucede con la irrevocabilidad, no pueda darse en actos de otros poderes públicos, pero desde luego resultaría muy difícil imaginar que los jueces pudieran desarrollar su cometido fundamental sin este previo condicionante. Para una opinión de contraste sobre esta cuestión, DíEZ-PiCAZo GimÉNEZ, L.: Régimen constitucional del poder judicial, cit., p. 20.

9 Díez-Picazo Giménez, L.: Régimen constitucional del poder judicial, cit., p. 25.

10 Como ha observado el Prof. Alzaga, en este proceso de atribución de la función judicial a un poder judicial independiente contribuyó decisivamente la Constitución de 1812 [Alzaga VillaAmil, O.: «La justicia en la Constitución de 1812», en Teoría y Realidad Constitucional, n. ${ }^{\circ}$ 28, Madrid, 2011, p. 243.

11 La importancia que tiene para John Locke el poder legislativo es lo que le hace entender que es quien se encarga de transferir el poder de aplicar la ley a determinados magistrados, esto es, en esencia lo que luego sería, una vez reelaborado por MONTESQuiEu, el poder judicial [LOCKE, J.: Ensayo sobre el gobierno civil, trad. Amando Lázaro Ros, Buenos Aires, 1955, p. 105]. 
garantizando los derechos de los ciudadanos ${ }^{12}$; de ahí que la función jurisdiccional tenga en este aspecto un carácter complementario respecto de la función legislativa. A pesar de las oscilaciones que ha sufrido la cuestión relativa al grado de sujeción que ha de tener el juez en un Estado de Derecho, hoy parece que la opinión más extendida desde el punto de vista constitucional es aquella que consiste en exigir al juez un alto grado de fidelidad al ordenamiento jurídico, sobre todo cuando éste se manifiesta a través de las fuentes formales en que en los sistemas democráticos suele expresarse la voluntad popular. Las sociedades democráticas no han renunciado a ver en las decisiones del parlamento la expresión de la voluntad popular de manera que los jueces tienen la obligación de hacer respetar la ley aun cuando no estén conformes con la solución jurídica que contenga. En eso se resuelve la legitimación democrática del poder judicial ${ }^{13}$.

El objeto de esta potestad es, pues, instrumental en la medida en que su ejercicio se atribuye para llevar a cabo una función que está perfectamente definida por la Constitución: juzgar y hacer ejecutar lo juzgado. Como señaló en su día LOEWENSTEIN, el poder judicial constituye la piedra final en el edificio del Estado democrático y constitucional de Derecho y la ley, y sólo la ley, es su único due$\tilde{n} 0^{14}$. En este sentido bien puede afirmarse que la Constitución ha optado claramente por dar preferencia a las decisiones que provienen del ejercicio de la función legislativa que a las que pudieran derivarse del ejercicio de la función jurisdiccional. Por eso ha reforzado las garantías de la independencia judicial precisamente con esta finalidad, evitando que otro tipo de factores pudieran entorpecer el ejercicio de esta actividad.

En este aspecto estoy seguro que lo que pretendió la Ley Orgánica del Poder Judicial fue que ningún factor apartara a los jueces de su obligación de cumplir la ley como resultado de la nueva legalidad democrática. Hay que tener en cuenta que no es suficiente con que exista un sistema básico de resolución de conflictos en el que la actividad del juez se reduzca simplemente a decir el derecho entre las partes sino que lo que se busca es el imperium que confiere su ejercicio, no tanto para evitar el desorden y la violencia derivada de la autotutela, sino para que prevaleciera el interés del Estado por imponer, no cualquier solución, sino la que sea exactamente el fruto de la decisión de la ciudadanía ha expresado en el parlamento ${ }^{15}$. Las normas jurídicas constituyen la síntesis de las distintas visiones o posi-

12 De ahí que se haya dicho con acierto que en este sentido la naturaleza del poder judicial es eminentemente conservadora, no porque políticamente lo sea en realidad, sino porque la decisión está asentada sobre la base de una norma cuyo contenido precede y condiciona el ejercicio de su actividad [ALZAGA VILLAAMIL, O.: Comentario sistemático a la Constitución Española de 1978, cit., p. 715].

13 González Granda, P.: Independencia del juez y control de su actividad, Valencia 1993, p. 102.

14 Loewenstein, K.: Teoría de la Constitución, trad. Alfredo Gallego Anabitarte, Madrid, 1976, p. 294.

15 Para FAirén Guillén, la superación de la litiscontestatio como origen y fundamento de la sentencia del juez es esencial para comprender este fenómeno [FAIRÉn GuIlléN, V.: «Una perspectiva histórica del proceso: la litiscontestatio y sus consecuencias», en Estudios de Derecho Procesal, Madrid, 1955, p. 38. 
ciones respecto a los problemas que pueden surgir entre los particulares; el Derecho bien puede ser entendido así como una suma de preferencias, cuyo contenido queda concretado y objetivizado a través de la ley. Por eso los jueces en el ejercicio de la potestad jurisdiccional se ven muchas veces obligados a desobedecerse a sí mismos y obedecer el criterio sustentado por la voluntad de la mayoría encarnada en la ley; es más, muchas veces la autoridad moral del juez le viene dada, más por su capacidad de cumplir la ley, que por la libertad de aplicarla o no conforme a su propio criterio $^{16}$.

El término jurisdiccional se reserva para referirse a la actividad que desempeñan jueces y magistrados integrados en el poder judicial cuando ejercitan la potestad jurisdiccional, juzgando y haciendo ejecutar lo juzgado. Es por ello que desde el punto de vista de la existencia, el poder judicial ni preexiste al Estado ni es independiente de él; tampoco preexiste a la Constitución, sino que tiene su origen en la Constitución misma; es, si se quiere decir así, un poder que constitucionalmente se constituye al tiempo que los demás poderes del Estado. Por eso el poder judicial es un auténtico poder del Estado, siendo éste su titular; no sus integrantes. En cambio, tiene la particularidad de que el Estado únicamente lo puede ejercer a través de un complejo orgánico de sujetos, jueces y magistrados, a quienes se les ha atribuido específicamente el ejercicio de la potestad jurisdiccional ${ }^{17}$. Conviene hacer notar que la potestad jurisdiccional no la confiere el parlamento; tampoco es la ley quien les atribuye a los jueces la función de juzgar, sino la Constitución misma y exclusivamente con una finalidad, que resuelvan las controversias entre los ciudadanos mediante la aplicación del Derecho al caso concreto.

Es verdad que en la medida en que a los sujetos a quienes se les atribuye la potestad jurisdiccional no lo hacen al margen del resto de la estructura organizativa del Estado, de este enunciado no debe extraerse la conclusión de que los jueces ostentan poder alguno; los jueces son detentadores de una potestad pero no de un poder. En este sentido, el poder judicial, aun siendo un poder del Estado, no está llamado a ser una manifestación del poder político ${ }^{18}$.

Considero de suma importancia este punto de vista ya que el principio de división de poderes a veces ha sido utilizado como eslogan ambivalente con el

16 Como recuerda IHERING, uno de los méritos del Derecho es haber logrado separar la norma del sentimiento moral que subjetivamente provoca en el juez la aplicación de la ley donde en su opinión es preciso tener gran firmeza de carácter y un juicio muy seguro para vencer al sentimiento y aplicar la regla abstracta en interés de la misma regla [IHERING, R.: El espíritu del derecho romano, trad. Fernando Vela, Madrid, 1962, p. 1271 .

17 Díez-Picazo Giménez, L.: Régimen constitucional del poder judicial, cit., p. 34

18 Este fenómeno ha sido desde Loewenstein descrito como judicialización de la política y que tiene lugar cuando los tribunales a través de actuaciones camufladas de sentencias judiciales se erigen en árbitros de la dinámica de la acción de gobierno con lo se corre el riesgo de que, o bien la decisión judicial no sea respetada, lo que amenazaría a la solidez del Estado de Derecho, o bien que la decisión política sea sustituida por parte de quienes carecen la legitimación democrática para intervenir políticamente [LOEWENSTEIN, K.: Teoría de la Constitución, cit., p. 325]. 
propósito de reivindicar una posición de supremacía de los jueces respecto del resto de los poderes del Estado. En la terminología constitucional, integran el poder judicial, pero ni son dueños ni son cotitulares de él, por lo que, aunque de la expresión utilizada por Constitución pudo extraerse en algún momento una opinión en este sentido, no dejó de ser luego un mero espejismo de la realidad ${ }^{19}$.

En este mismo aspecto, hay quienes opinan que, en cuanto poder del Estado, la composición de su órgano de gobierno, debía tener un origen cuya legitimación le viniera directamente de los ciudadanos a través del parlamento ${ }^{20}$, hasta el punto de que hace tiempo llegó incluso a considerarse que una de las principales causas estructurales que estaban perturbando el funcionamiento del poder judicial era precisamente el empecinamiento de seguir manteniendo, a las puertas del siglo XXI, el mismo modelo que se creó en el siglo XVIII ${ }^{21}$. Como uno puede imaginarse, en cuanto al poder judicial se refiere, a su finalidad y a su existencia, su función no puede ser otra que la de asegurar la prevalencia de la ley como medio de precaverse de la arbitrariedad de los gobiernos y de sus gobernantes ${ }^{22}$. La división de poderes, tan intuitiva y genialmente recreada por MONTESQUIEU, fue diseñada para garantizar el libre ejercicio de los derechos de los ciudadanos y asegurar la independencia de aquellos a quienes se encarga esta actividad ${ }^{23}$.

La simple atribución de funciones a un selecto y escogido grupo de jueces no asegura su independencia si ésta no va acompañada de los medios tanto para exigirla como para garantizarla. Confiar el ejercicio de la potestad jurisdiccional a un cuerpo de funcionarios del Estado distinto del resto de los servidores públicos, no es suficiente garantía ${ }^{24}$. Hay que tener en cuenta que el Estado no atribuye la potestad jurisdiccional a los jueces porque sean independientes sino porque espera que lo sean en atención a las garantías que se les ha atribuido ${ }^{25}$.

Así pues, la cuestión acerca de si el poder judicial es un auténtico poder del Estado, debería quedar resuelta, no tanto por el hecho de que al frente de ese

19 De la Oliva Santos, A.: «La demolición de la administración de justicia en la futura Constitución de 1978», en Revista de Derecho Procesal, 1978, 2-3, p. 405.

20 Ledesma Bartret, F.: «Cinco años y medio en el Ministerio de Justicia», cit., p. 1764.

21 En uno de los medios de expresión intelectual del socialismo español se llegó a afirmar que la interesada, confusa y errónea versión de la separación de poderes y la independencia judicial que a veces se ofrece, se ha convertido en un mito, esto es, en unas creencias irracionales defendidas dogmáticamente, cuya indefinición permite que sirvan para todos los propósitos [«Temas para el Debate», n. ${ }^{\circ}$, junio-1995, p. 5].

22 García de EnTERría, en un trabajo que se ha convertido en un clásico, ha señalado que uno de los elementos fundamentales con que reaccionar frente al absolutismo fue precisamente garantizar el principio de legalidad, germen del Estado de Derecho [GARCía DE ENTERRÍA, E.: Revolución francesa y administración contemporánea, Madrid, 1972, p. 10].

23 Pedraz Penalva, E.: «De la jurisdicción en la teoría de la división de poderes de Montesquieu», en Constitución, jurisdicción y proceso, Madrid, 1990, p. 29.

24 Mosquera, L.: «La posición del poder judicial según la Constitución Española de 1978», en $L a$ Constitución Española de 1978, Estudio sistemático dirigido por Alberto Predieri y Eduardo García de Enterría, Madrid, 1980, p. 694.

25 Díez-Picazo Giménez, I.: Comentarios a la Constitución Española, Dirs.: M. a Emilia Casas Baamonde y Miguel Rodríguez-Piñero y Bravo-Ferrer, Madrid, 2008, p. 1838. 
poder haya un órgano de gobierno independiente del poder político sino fundamentalmente porque incorpora, al igual que el resto de los poderes, la idea de autoridad o de supremacía, en la medida en que impone, no ya su voluntad, sino la voluntad mayoritaria de los ciudadanos expresada en la ley, asegurando de esta manera la observancia de las normas jurídicas y las garantías de los derechos fundamentales de los ciudadanos ${ }^{26}$.

\section{EL CONSEJO GENERAL DEL PODER JUDICIAL: SAGGIO POLEMICO O ENIGMA INDESCIFRABLE}

Con relativa frecuencia al abordar el estudio de esta institución se suele prescindir de las circunstancias políticas en las que se aprobó nuestra Constitución, un aspecto que siempre hay que tomar en consideración al analizar el contenido de sus disposiciones; nuestra Constitución, al igual que otras muchas, fue como todos sabemos el resultado de una situación y no de una decisión ${ }^{27}$ y, por lo tanto, es un texto elaborado por un pueblo que disponía de memoria histórica.

La constitucionalización de muchos de sus preceptos obedece a veces tanto a un estado de ánimo como a un estado de opinión; con razón, el contenido de las normas que la Constitución dedica al poder judicial probablemente fuera la consecuencia de una labor llamada a hacer frente a una multitud de situaciones existentes y concurrentes durante el proceso de su elaboración. Por eso, quizás una de las pretensiones fundamentales de sus redactores fuera la de asegurar la independencia de los jueces al tiempo que se procedía a democratizar el gobierno del poder judicial.

Una vez descartado el ideal místico de un poder judicial gestionado por sus propios servidores, esta finalidad se intentó alcanzar mediante la creación de un órgano propio que estuviera lo más alejado posible, tanto del Gobierno, como de aquel sector de la judicatura que más influencia podría haber ejercido en ese momento $^{28}$. Es muy posible que los redactores de la Constitución tampoco entonces tuvieran una idea muy exacta de lo significaba el gobierno del poder judicial cuando pensaron en introducir el Consejo General del Poder Judicial, y de tenerla, es muy posible que su idea no coincidiera con la que cada uno de ellos tuviera en ese momento, ni seguramente fuera la misma que la que podamos tener ahora ni con la que se pueda llegar a tener dentro de unos años, pero sí sabían lo que querían.

26 En general, todos los tratadistas coinciden en esta formulación; vid. XIOL Ríos/GonZÁLEZ RIVAS/ Rodríguez-Zapata PÉrez: El poder judicial y su Consejo General en el Estado social y democrático de Derecho, Madrid, 1986, p. 16.

27 Fonsthoff, E.: El Estado en la sociedad industrial, edición a cargo de Jaime Nicolás Muñiz y Luis López Guerra, Madrid, 2013, p. 43.

28 Con expresa referencia a ello, por ejemplo, Peces-BArba, G.: La elaboración de la Constitución de 1978, cit., p. 78 y Vives Antón, T.: Comentarios a la Constitución Española, cit., p. 1824. 
La creación del Consejo General del Poder Judicial respondía al decidido propósito de mantener al poder judicial lo más alejado posible del área de influencia del poder gubernamental. Así pues, dando por supuesto que el bien informado lector de esta revista tan especializada conoce, no creo necesario reproducir el catálogo de argumentos que se han ofrecido a lo largo de estos años sobre esta importante cuestión ${ }^{29}$. Aunque a la vista de todo lo que se ha escrito y todo lo que se ha dicho sobre este órgano y las vicisitudes que ha sufrido desde su constitución puede que siga resultando más fácil seguir insistiendo más en lo que no es que en lo que debería ser o lo que debiera haber sido (STC 108/1986). Así pues de lo que estamos seguros es que es, como así se ha llegado a calificar, uno de los órganos de naturaleza más polémica de cuantos prevé la Constitución ${ }^{30}$.

En este aspecto, es verdad que la Constitución no fue muy original en la fórmula, ni fue demasiado explícita a la hora de definir en qué habría de consistir el gobierno del poder judicial ni cuáles tendrían que ser las funciones que debería desempeñar, pero parece descartado que ni por su especial configuración ni por la privilegiada posición que ocupa como órgano constitucional hubiera querido que fuera un órgano de autogobierno del poder judicial ni que le correspondiera definir o determinar una determinada política en materia judicial, entre otras razones porque esta función le estaba reservada constitucionalmente al Gobierno. Pero sî hacer un poder judicial verdaderamente independiente y que contribuyera a mejorar la administración de justicia y a corregir aquellas actuaciones contrarias al ejercicio de la función que desempeñan jueces y magistrados ${ }^{31}$.

Tampoco creo que la Constitución pretendiera entregar el gobierno del poder judicial a quienes, como los partidos políticos, podrían estar en las mismas condiciones de interferir en el poder judicial de la misma manera que antes lo había hecho el poder ejecutivo, pero lo cierto es que cada vez que llegaba el momento de proceder al nombramiento de los vocales, el espectáculo público y el clima político que ha rodeado el proceso de elección, era todo menos ejemplar. Y esto ha sido debido en parte a que el órgano de gobierno del poder judicial ha sido uno de los más codiciados por dos instituciones que se han distinguido claramente por su enorme voracidad en cuanto a la metodología utilizada para la consecución de sus objetivos estratégicos ${ }^{32}$. Probablemente ello se deba a que algunos no quisieron que fuera un poder tan neutro como a Montesquieu le hubiera

29 Vid. Xiol Ríos/González Rivas/Rodríguez-Zapata Pérez: El poder judicial y su Consejo General en el Estado social y democrático de Derecho, cit., p. 16.

30 Díez-Picazo Giménez, L.: Régimen constitucional del poder judicial, cit., p. 132.

31 Como se ha indicado, la reforma de 1994 emprendió una serie de modificaciones para tratar de impulsar un modelo en el que fuera el Consejo General del Poder Judicial quien asumiera el papel de gobierno del poder judicial en el más amplio sentido de la palabra con el objetivo de que fuera el encargado de definir la política judicial. La atribución de sus competencias y la denominada potestad reglamentaria externa no puede entenderse más que en esa clave.

32 El término de instituciones voraces («greedy institutions») fue acuñado por el sociólogo norteamericano Lewis A. Coser y a mi modo de ver tanto las asociaciones judiciales como los partidos políticos responden 
gustado; de no ser así, no se explica que lo primero que hayan hecho todos los partidos políticos nada más alcanzar el poder haya sido precisamente abordar la reforma del Consejo General del Poder Judicial. Y si no, tampoco se explica cómo el procedimiento para la selección de los vocales haya llegado a dar lugar a un conflicto constitucional de tal envergadura como el que se planteó en 1985 con motivo de la presentación al parlamento del proyecto de Ley Orgánica del Poder Judicial ${ }^{33}$ y menos aún, cómo se llegó a aprobar una reforma con la exclusiva finalidad de modificar el régimen de mayorías para la adopción de acuerdos ${ }^{34}$ y de cómo, inexplicablemente para algunos (y explicablemente para otros), pero en todo caso, en contra de la decisión adoptada con este fin por el Consejo de Ministros y de la propuesta que al efecto elaboró la comisión creada con este propósito, se llegó a última hora a modificar el procedimiento propuesto para la designación de los vocales del Consejo General del Poder Judicial.

En mi opinión, un órgano al que se le confió la trascendental función de velar por el prestigio del poder judicial y garantizar de esa manera el principio de separación de poderes, no se merecía el vapuleo legislativo al que se le ha sometido; porque quien ha sufrido realmente las consecuencias de esta situación han sido, además de la dignidad del propio órgano, aquellos a quienes representa, los jueces y magistrados, trasladando al ciudadano y a la opinión pública una permanente sombra de sospecha sobre la neutralidad de los jueces a quienes él mismo ha nombrado.

De ahí que mientras no se decida cambiar la composición del Consejo General del Poder Judicial a través de la oportuna reforma constitucional, lo adecuado hubiera sido, como así planteamos quienes formamos parte del grupo de trabajo que elaboró hace unos años una propuesta de reforma, que la selección de los vocales de procedencia judicial se efectuara mediante un procedimiento en el que los doce vocales fueran elegidos a través de un sistema electoral en el que, a diferencia de los sistemas anteriores, garantizase la máxima representación de todos ellos.

Y eso desde luego sólo podía conseguirse con un sistema que atribuyera a todos los miembros de la carrera judicial la condición de elector y de elegible. Alguien podrá pensar que en realidad son las asociaciones judiciales quienes de verdad conocen lo que quieren los jueces pero, desde luego, es lo más democrático que se nos ocurrió, que no es sino permitir que los propios jueces fueran quienes pudieran votar a sus representantes en lugar de hacerlo a las asociaciones ju-

a los rasgos que este autor describe para caracterizarlas de esa manera [COSER, L.: Las instituciones voraces, trad. Sergio Lugo Rendón, México, 1978, p. 11].

33 Un detallado análisis del conflicto: Fairén Guillén, V.: Comentarios a la Ley Orgánica del Poder Judicial de 1 de julio de 1985, Madrid, 1986, p. 117.

34 Ley Orgánica 2/2004, de 28 de diciembre, que se presentó formalmente con el propósito de fomentar el diálogo y el consenso en la adopción de determinados nombramientos, vino a la postre a sustituir el criterio tradicional seguido hasta ese momento por otro en que la adopción de acuerdos tuviera que ser mediante una mayoría cualificada de las tres quintas partes de sus integrantes. 
diciales $^{35}$. Y todo ello sustentado en una idea que por atrevida no fuera menos sensata y razonable que otras y que consiste en admitir que, como expusimos y defendimos, las virtudes individuales son tan importantes como el ideario de los grupos organizados. Por lo tanto, llegamos a la conclusión, aun no desmentida, de los jueces están perfectamente capacitados para elegir lo que más les convenga sin necesidad de que haya otros que les ayuden a hacerlo ${ }^{36}$.

Es más, si hubiera que atribuirle una asignación numérica al resultado que este sistema de elección supone, valorado en términos de autogobierno, es decir, en función del grado de participación que el gobernado tiene en la selección del gobernante, podríamos llegar a afirmar que el Consejo General del Poder Judicial habría podido tener al menos tres quintas partes de vocales elegidos directamente por los jueces, algo que seguramente hubiera resultado del agrado de quienes, como James Madison, pensaban que para garantizar eficazmente la separación de poderes, cada una de las ramas debería estar organizada de tal manera que cada uno de sus miembros tuvieran la menor influencia posible en el nombramiento de los miembros de las otras ramas ${ }^{37}$.

Aun así, lo cierto es que a pesar de las dificultades por las que ha tenido que atravesar el Consejo General del Poder Judicial y las críticas de las que ha sido objeto $^{38}$, considero no obstante que si tenemos en cuenta que si este órgano se concibió más para desapoderar que para apoderar, el objetivo se ha conseguido y, al menos en este aspecto, ha sido un elemento que ha contribuido a garantizar un alto grado de independencia judicial. El Consejo General del Poder Judicial no son sólo los veinte vocales, sino que responde a una estructura orgánica dispuesta para la gestión y para la administración de todo lo concerniente al ámbito de las atribuciones que, como órgano de gobierno, la Constitución le ha encomendado; su función no se encuentra exclusivamente orientada a la deliberación y la decisión sobre lo que se considere importante. Son miembros de una corporación pública; no simplemente electores. Si así se hubiera querido, habría bastado con reunirlos en una mesa camilla cada vez que hubiese que efectuar un nombramiento de un magistrado del Tribunal Supremo, una función que, aunque sea la que más visibilidad tiene desde el punto de vista de la opinión pública, no es ciertamente la única, ni siquiera la más importante.

35 Tan es así, que la reforma operada por la Ley Orgánica 2/2001 llegó al esperpento de obligar al parlamento a elegir entre quienes las propias asociaciones previamente habían seleccionado. En todo ello late a mi juicio el temor de la clase política a enfrentarse a las asociaciones con los que mantienen una afinidad ideológica y a las asociaciones a enfrentarse con los políticos con los que simpatizan.

36 Así se optó por un sistema proporcional a través de candidaturas de lista a las que se les aplicó la llamada fórmula Hare que consiste en dividir el número de votos válidamente emitidos a la candidatura por doce, que es número de puestos a seleccionar.

37 Alexander Hamilton/James Madison/John Jay: «El federalista», edición Ramón Máiz, Madrid, 2015, p. 397.

38 Un claro exponente de esta posición lo encontramos en NiETo, A.: El desgobierno del poder judicial, Madrid, 2004 y en ÍñIGuez HernándeZ, D.: El fracaso del autogobierno judicial, Pamplona, 2008. 
En la actualidad, dada la complejidad de la actividad que soporta este órgano en lo que se refiere a la administración de los recursos humanos y materiales relacionados con la justicia, cumple un cometido institucional de enorme relevancia al haberse hecho cargo de buena parte de lo que se ha denominado la administración de la administración de justicia o la administración de la jurisdicción ${ }^{39}$, una tarea que comparte, y probablemente nunca podrá ya dejar de compartir, con las Comunidades Autónomas ni con el Gobierno ${ }^{40}$.

Ya sabemos que la Constitución atribuyó al legislador la facultad de establecer las funciones que habría de asumir como órgano de gobierno, en particular en materia de nombramientos, ascensos, inspección y régimen disciplinario; por supuesto no le dice la Constitución que haya de asumirlas, sino que ordena a la ley que sea ella quien establezca cuál deba ser su función en relación con tales materias. La Ley Orgánica del Poder Judicial procuró en este aspecto ser coherente con el sistema constitucional y le atribuyó prácticamente competencia plena en todas ellas; tal vez hubiera sido una burla el que la ley devolviera a otro poder del Estado lo que la Constitución quiso dejar en manos del poder judicial.

En cambio, erróneamente asumió algunas competencias que en mi opinión no debería haber tenido, como por ejemplo la llamada potestad reglamentaria externa que, como cabe imaginar, no es más que la forma elegante de describir la atribución al Consejo General del Poder Judicial del ejercicio de la potestad de dictar normas vinculantes en el ámbito judicial incluso para quienes no deberían verse afectados por ellas ${ }^{41}$, o aquellas que constitucionalmente pertene-

39 Guaita, A.: «Administración de Justicia y administración judicial», en Revista de Derecho Procesal, IV, 1968, p. 11.

40 La cuestión sobre el papel que desempeñan las Comunidades Autónomas en sus relaciones con el poder judicial, ha sido objeto de enormes controversias, sin que se haya alcanzado una solución adecuada. El Tribunal Constitucional, respaldando la constitucionalidad de las llamadas cláusulas subrogatorias que en su momento incluyeron los distintos Estatutos de Autonomía, les ha permitido ejercer las atribuciones que la Ley Orgánica del Poder Judicial reservaba inicialmente al Gobierno de la Nación (SSTC 56/1990, 62/1990 y 97/2001 y, especialmente, las SSTC 31/2010, 163/2012 y 224/2012). La gran mayoría de las Comunidades Autónomas decidieron en un principio destinar parte de la financiación que reciben del Estado a invertir en los órganos jurisdiccionales radicados en su territorio, lo que ha alimentado su interés en intervenir en las políticas que afectan a su Comunidad Autónoma. La sensación de ser al mismo tiempo juez y parte en procesos en los que existe una clara contraposición de intereses no ha contribuido ni mucho menos a la buena imagen de la justicia y menos aún la posibilidad que tienen sus asambleas legislativas de nombrar a un magistrado de la Sala Civil y Penal del TSJ, que es precisamente la encargada del enjuiciamiento de los altos cargos del gobierno de cada Comunidad Autónoma.

41 La potestad reglamentaria externa, que supone en sí misma la atribución de un espacio que la Constitución encomendó a otros poderes del Estado, se consolidó con la reforma de la Ley Orgánica 16/1994, de 8 de noviembre; bien es verdad que gran parte de este cambio vino motivado por la necesidad de completar el proceso iniciado años atrás tendente a desapoderar al poder ejecutivo de las competencias que aún conservaba sobre la administración de la administración de justicia. Como algún autor ha tenido el acierto de subrayar, a esta decisión política probablemente no fuera ajena la consecuencia de tener que entregar a las Comunidades Autónomas, porque así lo exigían los Estatutos, todas las competencias que se reservaban o se atribuyeran al Gobierno del Estado [Víctor Moreno Catena, en el prólogo a la decimotercera edición de la «Ley de Orgánica del Poder Judicial y Estatutos orgánicos», Tecnos, Madrid, 1999]. 
cen claramente al poder ejecutivo, como la referida a la dirección de la política exterior en materia judicial o la representación del poder judicial en el ámbito internacional ${ }^{42}$.

En este sentido, considero enormemente perturbador el ejercicio de la función consultiva, al menos cuando se trata de informar y, por lo tanto, de evaluar, muchas veces con criterios fundamentalmente ideológicos o de oportunidad política, las iniciativas legislativas del gobierno contenidas en distintos anteproyectos de ley que se le remiten. A menudo sus decisiones son presentadas ante la opinión pública como provenientes del poder judicial cuando sólo provienen únicamente de su órgano de gobierno al que se le da la oportunidad de pronunciarse sobre aspectos que alcanzan en muchos casos, bien al ámbito propio de la discrecionalidad de la acción de gobierno y, en otros, anticipan decisiones que habrían de corresponder a jueces y magistrados en ejercicio de la potestad jurisdiccional y, en último extremo, al Tribunal Constitucional. En mi opinión, el ejercicio de esta labor debería quedar reducido a las iniciativas que afecten a las competencias que afecten directamente a la organización y funcionamiento del poder judicial (art. 561 LOPJ).

$\mathrm{Y}$ ahora que ya sabemos que entre las atribuciones del Consejo General del Poder Judicial no se encuentra la de definir estrategias de gobierno en materia de política judicial, reservada constitucionalmente al poder ejecutivo, el debate ha acabado nuevamente circunscrito a dos cuestiones fundamentales: la de cómo se elige a los vocales y, como derivación del mismo, si atendiendo a sus actuales atribuciones, su estructura interna es la idónea para el desempeño de las funciones se le han encomendado ${ }^{43}$.

En este aspecto, más allá de la obstinada insistencia sobre cuál fue o no fue la intención de los redactores de la Constitución, una cuestión que no sabemos si ha alcanzado el suficiente nivel de sofisticación y sobre el que en principio no existiría más duda que la que interesadamente quisieran plantear los representantes de la clase política o las asociaciones judiciales, la doctrina desde hace tiempo viene propugnando la conveniencia de buscar una fórmula que haga más ágil, más operativo y más eficiente el funcionamiento del Consejo General del Poder Judicial.

De suerte que, entre las soluciones posibles, la que al parecer ha suscitado mayores apoyos y resultaba finalmente la más viable sin tener que abordar una reforma constitucional era la que pasaba por aproximar el funcionamiento de este órgano al sistema que ya existía en otros órganos de similar naturaleza. Esta fór-

42 Cuestiones todas ellas que fueron objeto de revisión por la modificación llevada a cabo por la Ley Orgánica 4/2013; también fue objeto de revisión la materia referida a la autonomía presupuestaria de manera que es el propio Consejo quien elabora una propuesta de presupuesto y efectúa el control del gasto pero se integra en los Presupuestos Generales del Estado.

43 Un sector de la doctrina ya advirtió en su momento de los riesgos que entrañaba esta solución: XIOL Ríos/González Rivas/Rodríguez-Zapata Pérez: El poder judicial y su Consejo General en el Estado social y democrático de Derecho, cit., p. 124. 
mula, por la que ya se habían inclinado algunos autores más influyentes ${ }^{44}$, consiste básicamente en distribuir las funciones del Consejo General del Poder Judicial entre una Comisión Permanente, de composición reducida y con un régimen de dedicación exclusiva, y las que deban atribuirse al Pleno. Todo ello basado en la constatación de que no es un órgano consultivo y, por lo tanto, es conveniente adaptar su funcionamiento en atención a la importancia de sus decisiones, pues tal como estaba configurado, su estructura interna respondía a una distribución absolutamente inadecuada ${ }^{45}$.

No creo necesario insistir en que la idea, a la que además contribuyeron una serie de factores externos, fue finalmente bien acogida por el Gobierno e incorporada (no sin cierta oposición de un sector de la judicatura) a la reforma que impulsó con la aprobación de la Ley Orgánica 4/2013. En este aspecto, sea cual sea el reproche que desde el punto de vista de la valoración política tenga que tener esta forma de distribución de competencias respecto a la independencia del Consejo General del Poder Judicial (si acaso la tiene), la reforma llevada a cabo en el año 2013 no tendría por qué ser más cuestionada respecto de su encaje constitucional que la de 1985, al menos si se interpreta a la luz de la doctrina que el propio tribunal utilizó en 1986 (STC 108/1986) ${ }^{46}$.

Por eso, quienes tras esta reforma se envuelven ahora en la bandera de la independencia judicial deberían considerar si su actitud ha sido o no coherente con los criterios que defendieron durante las sucesivas que ha sufrido la Ley Orgánica del Poder Judicial desde 1985, no vaya a ser que aquélla sentencia, la STC 108/1986, no haya sido más que el reflejo de un estado de ánimo que, en el fondo, viniera a sostener que cualquier fórmula que encaje con la Constitución pero coherente con una determinada estrategia política es, por lo tanto, constitucional (lo cual evidentemente no es cierto $)^{47}$.

No cabe duda de que la reforma que se anunció y que se acaba de consumar, incrementando de cinco a siete el número vocales de la Comisión Permanente, era

44 Por ejemplo, Aguiar de Luque [Comentarios a la Constitución Española, cit., p. 1897 y en «Las recientes reformas en materia de poder judicial en su dimensión orgánica», en El poder judicial, Coordinador: Miguel Revenga Sánchez, Valencia, 2009, p. 51].

45 Moreno Catena, V.: en «Ley de Orgánica del Poder Judicial y Estatutos orgánicos», editorial Tecnos, Madrid, 1999; considera además que la distinta procedencia de los vocales supone otro elemento que hace enormemente difícil el proceso de toma de decisiones ya que la formación de grupos y por ende el fraccionamiento de los vocales resulta poco menos que inevitable.

46 Algunos autores la han tildado de contrarreforma, un apelativo que aunque tiene un clara intencionalidad crítica, no sé si se corresponde realmente con el contenido de la reforma [Í̃̃IGUEZ HERNÁNDEZ, D.: «La contrarreforma del Consejo General del Poder Judicial», en Teoría y Realidad Constitucional, n. ${ }^{\circ}$ 34, 2014, p. 333].

47 Como ya en su momento tuvo ocasión de señalar DíEz-PiCAZo, si bien el sistema instaurado en 1985 de designación de los vocales del Consejo no puede decirse que fuera inconstitucional, del art. 122 de la Constitución no cabe extraer otra conclusión que la que se deduce de su contenido, atendiendo a la finalidad y la forma de selección de sus integrantes que quedó claramente expresada en ella [DíEz-PicAzo GiménEz, L.: Régimen constitucional del poder judicial, cit., p. 141]. 
una decisión que más bien parece haber sido el resultado de un acto de desagravio hacia quienes consideraron que se habían visto más afectados por esta reforma y, desde luego, no contribuye a la idea de que aquella propuesta legislativa no fue improvisada sino fruto de una reflexión serena, meditada, nacida del convencimiento de que era una buena solución de entre las posibles, pero que, finalmente, no es que no haya encontrado su lugar, sino que los demás, los que esperaban más de ella, al parecer no han sabido atribuírselo.

Esperemos pues que esta nueva modificación no contribuya a pensar que la normativa que regula una institución, tan fundamental para la supervivencia de la democracia, está condenada a permanecer eternamente en precario simplemente porque alguien le interese seguir pensando que sigue siendo un acertijo envuelto en un misterio y dentro de un enigma («a riddle, wrapped in a mystery, inside an enigma»).

No confiamos mucho en que pueda llegar a ser así. Es verdad que el hecho de que el partido que lo esgrimió como objetivo programático de su ideario político haya renunciado por actos propios a volver al sistema de elección directa de los doce vocales del Consejo General del Poder Judicial, habrá convertido en irrealizable cualquier intento de modificar el modelo ya existente en aquella misma dirección, y partiendo de la base de que sería absolutamente inexplicable cualquier intento que pretendiese dicha formación política por justificar un posterior cambio de opinión en la dirección contraria a la que lo acaba de hacer, convierte asimismo en irrealizable cualquier tentativa de abordar una reforma de esta naturaleza. Ahora bien, si la situación política cambia, dependiendo en el sentido en que lo haga, a buen seguro que es muy posible igualmente que alguien, es decir, otra formación política, pueda incluso llegar a plantearse una nueva reforma y obligar a cada uno de los partidos mayoritarios a reconducir la situación o a ensayar nuevas fórmulas más o menos imaginativas de gobierno del poder judicial.

\section{INDEPENDENCIA Y RESPONSABILIDAD JUDICIAL. ¿EN QUÉ CONSISTE SER UN BUEN JUEZ?}

Hubiera sido muy difícil que con los condicionantes a los que hemos aludido el tema de la responsabilidad judicial hubiera formado parte de la agenda política de quienes han ocupado el poder desde la aprobación de la Constitución de 1978, aunque en honor a la verdad la cuestión sí fue objeto de un especial tratamiento tras la reforma de 1994 . Hasta ese momento, el tema de la responsabilidad de los jueces estuvo inicialmente asociado a la inamovilidad y no a otro tipo de factores que tendrían que haberse tenido en cuenta para asegurar un correcto funcionamiento de la actividad jurisdiccional, como la idoneidad, la preparación jurídica el rendimiento o cualquier otro elemento que pudiera afectar a la calidad del servicio que la justicia presta a los ciudadanos.

No hace falta remontarse a la ya clásica alocución de MONTERo Ríos para subrayar la estrecha vinculación existente entre la independencia, la inamovili- 
dad y la responsabilidad judicial cuando en el acto de apertura de aquel año judicial de 15 de septiembre de 1870 advirtió a los jueces que allí se encontraban: sois inamovibles, pero entendedlo muy bien; sois inamovibles en vuestro cargo porque sois responsables de vuestros actos. No en vano, la utilización de la responsabilidad disciplinaria durante los periodos de regresión democrática fue el mejor aliado para neutralizar a los jueces ideológicamente contrarios al gobierno. Por eso nuestra Constitución que, como he dicho, tenía memoria, se encargó de proclamar como principio esencial de nuestro ordenamiento constitucional, junto a la independencia, el de la inamovilidad y, a reglón seguido, el de la responsabilidad judicial, porque hubiera sido inaceptable que la movilidad judicial pudiese llegar a afectar a la independencia como que la inamovilidad sirviera para amparar la impunidad. Porque por mucho que alguien pretenda ignorarlo, es sobre los jueces sobre los que individualmente recae esta responsabilidad; son ellos quienes tienen atribuido el ejercicio de la potestad jurisdiccional.

Que el ejercicio de esa potestad se encuentre condicionado a lo que en cada caso establezca la ley no quiere decir que toda su actividad se encuentre predeterminada por ella. La justicia es cosa de jueces, de mujeres y hombres que cada día administran justicia, a veces en condiciones difíciles y en las que influyen muchos factores a la hora acertar o de no acertar. Desgraciadamente conocemos cómo afecta la carga de trabajo en muchos servidores públicos y cómo esa carga de trabajo repercute, no sólo en la salud de los jueces y en la celeridad con que se administra justicia sino en su capacidad de encontrar la solución adecuada al caso.

Aparte de las medidas organizativas o propiamente estructurales que habría que adoptar en este sentido, ya hemos visto lo importante que es que existan mecanismos igualmente eficaces para garantizar la independencia de los jueces a la hora de juzgar pero no parece lógico que un país carezca de instrumentos para evaluar las conductas de quienes en el ejercicio de la potestad jurisdiccional administran justicia al margen de los criterios legales o contravienen a los principios constitucionales esenciales, porque, en definitiva, las resoluciones judiciales arbitrarias no sólo deslegitiman al juez que las pronuncia sino también al Estado que las respalda. Y aunque no existe ninguna garantía de que las decisiones adoptadas por los jueces sean siempre las correctas, no lo es menos que hay muchas más posibilidades de que jurisdiccionalmente no incurra en responsabilidad quien se equivoca cumpliendo la ley que quien lo hace sin cumplirla. La proclamación de la independencia de los jueces no es suficiente garantía si ésta no viene acompañada de un sistema de responsabilidad. La devoción por la independencia judicial no debería permitirnos ignorar este otro aspecto de la cuestión.

En aras a garantizar la independencia de los jueces, se entiende que la actividad jurisdiccional es controlable únicamente a través de los remedios que en cada caso establezcan las leyes procesales. La ley no permite examinar la actuación de los jueces en función del contenido de sus resoluciones, las cuales son inmunes al control de los órganos de gobierno del poder judicial. Pero la actividad jurisdic- 
cional va acompañada de otro tipo de actos coetáneos, previos o posteriores del juez que pueden hacernos dudar de la neutralidad de la decisión o ser indicadores de un mal funcionamiento de la justicia, algo que no es consustancial a la decisión pero que condicionan su credibilidad.

Es verdad que en toda decisión judicial está siempre presente el ejercicio de la libertad que tienen los jueces de elegir de entre varias soluciones jurídicas; por eso son independientes y, a la vez, responsables. Como puso de relieve ForsTHO$\mathrm{FF}$, la sentencia no se deduce llana y simplemente de la ley sino que es una decisión inseparable de una persona, el juez, sin la cual no es ni siquiera imaginable ${ }^{48}$; si los jueces se limitaran simplemente a hacer lo que la ley les dice nunca podría exigírseles responsabilidad, de manera que si actúan de manera antijurídica incurren en responsabilidad $^{49}$. El sistema de responsabilidad judicial se sustenta sobre la existencia de un juez que, siendo inmune en cuanto a ejercicio de su función, en muchas ocasiones no lo es tanto en cuanto al ejercicio de las actividades que desarrolla como miembro del poder judicial.

Erradicada de nuestro país la responsabilidad disciplinaria intraprocesal, que en el fondo responde a un modelo de judicatura jerarquizada hoy afortunadamente superada ${ }^{50}$, subsiste, como derivación de una manifestación de gobierno, la posibilidad de que sea el Consejo General de Poder Judicial quien asuma la potestad de sancionar los actos que respondan a una serie de comportamientos que reúnan ciertas condiciones legales. Con ello se aleja el peligro, existente durante el periodo preconstitucional, de que el ejercicio de la potestad disciplinaria pueda llegar a convertirse en un medio encubierto en manos del poder ejecutivo de influir en la promoción profesional del juez, lo que incidiría gravemente en su inamovilidad y, por tanto, en su independencia ${ }^{51}$.

En este sentido, siendo la responsabilidad penal de jueces y magistrados de base jurisdiccional, y suprimida la responsabilidad civil directa, la única forma de efectuar un control interno sobre estos hechos es atribuyendo esta labor al Consejo General del Poder Judicial que es quien responde ante los ciudadanos de lo que se hace en su nombre y, en particular, de la profesionalidad de los miembros que lo integran, adoptando en su caso las medidas que sean necesarias. No podemos olvidar que los jueces cumplen una importante función social ya que sus resoluciones afectan a cuestiones esenciales de la vida, la libertad y al patrimonio de los ciudadanos; así pues, a medida que su capacidad de influir en los ciudadanos es cada vez mayor, a su vez han de elevarse en la misma proporción los estándares reguladores de su responsabilidad.

48 Forsthoff, E.: El Estado en la sociedad industrial, cit., p. 98

49 Rovira Viñas, A.: «Jurisdicción y Constitución», en Revista de Estudios Políticos, 1998, n. ${ }^{\circ} 102$, p. 39; también en «Sin Justicia», en Revista Jurídica de la Universidad Autónoma de Madrid (RJUAM), n. ${ }^{\circ} 28$, 2013-II, p. 325.

50 González Granda, P.: Independencia del juez y control de su actividad, cit., p. 217.

51 Almagro Nosete, J.: Responsabilidad judicial, Córdoba, 1984, p. 105. 
En toda esta materia late un problema aun no suficientemente resuelto y que muchas veces impide al órgano de gobierno del poder judicial cumplir con su cometido de asegurar el correcto funcionamiento de la administración de justicia porque no todo puede arreglarse en la administración de justicia a golpe de expediente disciplinario. Ya sabemos que cuando a un juez se le pide que responda respecto a una infracción sancionable disciplinariamente no está pensando sólo en lo que el juez ha hecho (acción) o ha debido dejar de hacer (omisión), sino en lo que no debería de haber hecho o dejado de hacer. En todo caso, es verdad que en la práctica en esta materia no es la respuesta negativa ante lo mal hecho sino la amenaza o el temor a la imposición de la sanción lo que contribuye a conformar su comportamiento. Es decir en un en un régimen de corte funcionarial y pseudocorporativo, la retribución resulta en la práctica sencillamente ineficaz. Se puede desarrollar hasta el infinito el ámbito de la responsabilidad disciplinaria sin que tenga ningún efecto quizás debido a que se trata de un régimen fundado más en la disuasión que en la retribución, de lo que resulta su acentuada excepcionalidad en cuanto se refiere al número de sanciones que efectivamente impone; de ahí que algún autor haya llegado considerarla una auténtica ficción ${ }^{52}$, entre otras razones porque en mi opinión se aprecia un cierto retraimiento en la aplicación de la normas que regulan la responsabilidad disciplinaria y supongo también porque en ocasiones la sanción para la persona-juez es a veces tan excesiva que condiciona las decisiones que se adoptan en esta materia ya que, llegado el momento de la verdad, disuade más el temor a imponerla que lo que uno piensa que debería disuadir su mera existencia.

Por eso, a lo mejor habría que explorar otro sistema para que el órgano de gobierno de los jueces pudiera, sin merma de la independencia judicial, garantizar un adecuado funcionamiento de la administración de justicia; conviene tener en cuenta que, según las cifras que proporciona el propio Consejo General del Poder Judicial, en la mayor parte de las veces las infracciones disciplinarias son debidas (directa o indirectamente) a causas estructurales y a mi juicio podrían haberse evitado con un sistema mucho más racional del trabajo en los tribuna$\operatorname{les}^{53}$. Ya sabemos que por lo que ha hecho jurisdiccionalmente, el juez no responde ya que existe un sistema de recursos o de medios de impugnación que le cubre las espaldas ${ }^{54}$. Pero no en lo demás, en lo que no es jurisdiccional. A mi modo de

52 NiETO, A.: El desgobierno del poder judicial, cit., p. 164.

53 A mi entender la creación de los tribunales de instancia, órganos colectivos pero no colegiados, hubiera permitido sortear muchas de las dificultades que a diario se presentan en los juzgados que más sobrecarga de asuntos soportan, favoreciendo una metodología de trabajo mucho más racional y cooperativa, evitando así los inconvenientes que existen en la actualidad, donde el juez se encuentra muchas veces aislado y sin el necesario apoyo, ni de sus compañeros ni del resto del personal al servicio de la administración de justicia; desgraciadamente la solución no fue bien acogida por las autoridades regionales ni por los regidores locales ni por muchos jueces, que vieron en esta solución una amenaza a sus intereses personales o profesionales.

54 TOMÁs y Valiente, F.: «Independencia judicial y garantía de los derechos fundamentales», en Constitución: escritos de introducción bistórica, cit., p. 2599. 
ver la eficacia del sistema de responsabilidad judicial deja mucho que desear pues como hemos dicho, con demasiada frecuencia la sanción actúa como un elemento disuasorio a la hora de imponerla y no sirve para remediar las causas que la han originado $^{55}$.

Pero como se ha indicado, la confianza en el poder judicial pasa también por confiar en quienes administran justicia; y ya sabemos que muchas veces la buena imagen de la justicia no se extrae del sentido de sus resoluciones sino de la imagen que los ciudadanos tengan de sus jueces. Durante mucho tiempo la imagen del buen juez ha estado asociada a valores que, como derivación de las virtudes cívicas, uno supone que debería tener un juez ${ }^{56}$. En este aspecto, tal como ha tenido el acierto de poner de relieve la profesora Solla SASTRE, la recreación y elaboración a nivel normativo de cómo ha de ser un buen juez se ha elaborado históricamente bajo las categorías de la responsabilidad disciplinaria, hasta tal punto de que, así configurada, ésta ha sido en su opinión la gran invención del siglo XIX que, introducida a partir de la Ley de 1870, es cuando deja de ser la forma discreta en que la severa mano de los presidentes de los tribunales, como una manifestación de su superioridad, corregía los excesos y las deviaciones que observaban en la conducta de sus inferiores ${ }^{57}$.

Pero más allá de cualquier consideración que trate de prefigurar el paradigma de cómo deben comportarse los jueces en su esfera personal, la política de gobierno, incluida la que se refleja a través de la responsabilidad disciplinaria, debería estar básicamente orientada a que al frente de cada juzgado o tribunal se encuentren unos jueces celosos guardianes de su propia independencia y respetuosos con los principios y valores constitucionales y que, como empleados públicos, presten un adecuado servicio a los ciudadanos en el ejercicio de la potestad jurisdiccional.

La responsabilidad judicial no es un concepto monolítico; tiene varias facetas y requiere preguntarse no sólo quien debe ser responsable, si el juez o la institución a quien representa, sino ante quien y en consideración a qué, tanto por su comportamiento («behaviour accountability»), como por sus decisiones («decisional accountability») o por su actuación profesional («administrative accountability») y, no en menor medida, en qué casos debe ser aplicada. En este último aspecto, parece que en muchos casos se tiende más que a contemplar soluciones orientadas exclusivamente a lograr el castigo del infractor («hard»), por articular

$55 \mathrm{Vid}$. las consideraciones que Sergi Rosell hace en esta misma sentido: Holmgren, M: ¿Perdonar o castigar? Como responder al mal, 2014, p. 22.

56 La imagen y el paradigma de lo que debe ser un buen juez ha estado muy presente tanto en la cultura popular como en la literatura jurídica; son muy recomendables las reflexiones que lleva a cabo el Profesor Díez-PiCAzo sobre este particular [DíEz-PiCAzo PonCE DE LEón, L.: «El ejercicio del poder judicial y el acto de juzgar», en La seguridad jurídica y otros ensayos, Pamplona, 2014, p. 58].

57 Solla SAStre, J.: La discreta práctica de la disciplina. La construcción de las categorías de la responsabilidad judicial en España (1834-1870), Madrid, 2011, p. 24. 
respuestas que traten de evitar que un juez pueda volver a incurrir en actuaciones similares, evaluando hasta qué punto han podido concurrir circunstancias externas o estructurales que hayan podido llegar a condicionar la actuación sujeta a responsabilidad, incluso, introduciendo medidas que fomenten un buen funcionamiento de la justicia («soft») $)^{58}$.

Así pues, no se trata tanto de introducir criterios moralizantes como de someter el desempeño de la función judicial a unos estándares suficientemente razonables que generen confianza entre los justiciables y que permitan corregir todo aquello que, directa o indirectamente, conduzca o provoque comportamientos irregulares. Con ello se evitaría que la actuación del juez no viniera motivada por el temor a la sanción que en su caso pudiera imponérsele como por la satisfacción de haber actuado correctamente. Y probablemente es debido a la ineficacia de los sistemas de responsabilidad disciplinaria lo que haya determinado que últimamente, exista una tendencia mucho más acusada a la introducción de otro tipo de criterios que operan al margen de la responsabilidad profesional como sucede específicamente con la tendencia a impulsar la introducción de pautas de carácter ético aplicables al funcionamiento de los servidores públicos ${ }^{59}$.

Pero se puede seguir siendo un buen juez desde el punto de adecuación de la conducta personal y profesional a ciertos estándares éticos y no ser el juez que responda a los requerimientos que demanda la sociedad en el ejercicio de la jurisdicción atendiendo a su nivel de conocimientos, preparación técnica y compromiso con principios y valores constitucionales. No basta con que los jueces observen una conducta ejemplar; un buen juez debe saber tanto lo que es el Derecho como para lo que sirve. La competencia y la profesionalidad son elementos que deberían ser más tenidos en cuenta para adaptar el ejercicio de la potestad jurisdiccional a los nuevos tiempos; lo cual puede llevarse a cabo de varias maneras, incluso mediante controles previos de idoneidad en el acceso a la función judicial. Ya sabemos que el grado de independencia de los jueces de un país depende en parte de factores sociales y culturales pero el grado de confianza que los ciudadanos tienen de sus jueces depende en gran parte de la propia actitud que los jueces observen ante los casos que se les someten; en otras palabras, la confianza que los ciudadanos tengan de la independencia de sus jueces depende fundamentalmente de ellos mismos.

La integridad moral del juez es muy importante pero no es determinante para asegurar una decisión conforme a la ley. En este sentido, sin necesidad de

58 Así, siguiendo el criterio de Kate Malleson [«The new Judiciary», 1999, p. 37], vid. Sengupta, A.: «Judicial Accountability: A Taxonomy», en Public Law, n. ${ }^{\circ}$ 2, 2014, p. 262.

59 En el ámbito de la función pública, en el Estatuto básico del Empleado Público con su correspondiente Código de conducta (art. 52); también proliferan los códigos de buen gobierno en diversas áreas y códigos deontológicos; en el ámbito de la justicia, el Consejo General del Poder Judicial acaba de impulsar la creación de un código ético de la carrera judicial; un completo repertorio de materiales sobre esta cuestión puede encontrarse en: www.poderjudicial.es/cgpj/es/Temas/Transparencia/Buen-Gobierno-y-Codigo-etico/ Codigo-Etico. 
tener que someter a la judicatura a la prueba de las noventa y cinco tesis luteranas ni obligarles a la lectura de Cicerón («De officiis»), a lo mejor sería conveniente cambiar de estrategia e invertir los términos de la cuestión y atajar el problema de otra manera, con más transparencia, con más formación y más incentivos a la promoción profesional a través de una excelencia premiada y, desde luego (¡cómo no!), con un reforzamiento de los comportamientos éticos como ya se ha empezado a hacer en otros ámbitos de la actividad pública y privada ${ }^{60}$; a mi modo de ver, es preciso proyectar una cultura enfocada hacia la calidad del servicio que prestan los tribunales y aumentar los niveles de exigencia en materia de responsabilidad judicial.

\section{V. ¿QUÉ JUSTICIA QUEREMOS?}

Al final, y después de este breve análisis sobre el desarrollo que ha experimentado el poder judicial en estos últimos treinta años es posible avanzar algunas conclusiones. La primera de ellas tiene que ver con la importancia que ha adquirido el poder judicial desde la aprobación de la Ley Orgánica del Poder Judicial. Ya sabemos que la fe en el poder judicial ha sufrido históricamente grandes oscilaciones y como nos ha hecho notar Tomás y Valiente, a pesar de que sea verdad que hay quienes presumen de defender las tesis de Montesquieu sin haberlo leído $^{61}$, lo cierto es que, siendo lógico que el autor del Espíritu de las Leyes no fuera el más entusiasta defensor del poder judicial toda vez que su teoría se formuló en respuesta a una situación concreta y determinada, en nuestro país se han dado pasos muy importantes atendiendo los niveles de calidad y de exigencia en el poder judicial (incluso sin necesidad haberlo leído).

Y esto es muy importante. En sociedades como la nuestra, donde el poder político está básicamente concentrado en los partidos políticos y donde no sería un eufemismo seguir calificándolo como un país dominado fundamentalmente por el poder de los partidos políticos ${ }^{62}$, los jueces desempeñan un papel esencial en la defensa de los derechos y libertades de los ciudadanos, no sólo porque resulta un instrumento de resolución de conflictos sino porque representan un contrapeso frente a la posible arbitrariedad de los poderes públicos, esto es, frente al po-

60 Sobre este cambio de orientación y algunas propuestas interesantes, vid. Ruiz Miguel, A.: «Vigilantes y vigilados: prevaricación judicial y normas sin sanción», en Jueces para la Democracia, n. ${ }^{\circ}$ 81, 2014 , p. 97.

61 Tomás y Valiente, F.: «Poder judicial y Tribunal Constitucional», en Poder Judicial (Especial XI), Madrid, 1986, p. 16.

62 García-Pelayo, M.: Estado de Partidos, Madrid, 1996. Algunos ha ido más allá al asegurar que es tal la influencia que ejercen los partidos en el legislativo y en el ejecutivo que el principio de separación de poderes se reduce, de hecho, a garantizar la independencia de jueces y tribunales [DE EsTEBAN-López GUERRA, El régimen constitucional español, Barcelona, I, 1980, p. 237], afirmación que, siendo así, debería en mi opinión haber tenido un mayor reflejo en el Código Penal (art. 492 CP). 
der ejecutivo y, como derivación del mismo, el poder legislativo. Es más, nunca como hasta ahora las decisiones judiciales habían tenido tanta importancia como hoy en día.

El problema de desapoderar no es tanto el efecto que esto supone desde el punto de vista de quienes pierden la capacidad de influir sino en las consecuencias que tal desapoderación ocasiona, pues hay decisiones que necesariamente es preciso seguir encomendando a alguien para que el sistema siga funcionando correctamente; y salvo que prefiramos un sistema automático basado en la pura aplicación de la antigüedad, no veo inconveniente alguno de que sea el Consejo General del Poder Judicial quien asuma esta función. La sociedad española ha acabado dándose cuenta del fracaso que ha supuesto para el país tener instituciones dotadas de un alto grado de autonomía pero que actúan de forma muy corporativa y sin controles externos que supervisen su gestión; confiemos en que la nueva realidad que nos toca vivir nos haga recapacitar sobre la esencia de cada una de ellas.

En definitiva, la cuestión a veces no es cómo se designan a los vocales sino cuál es el uso que éstos hacen de esa prerrogativa. Porque, puestos a suponer, a lo mejor hay que admitir que si de verdad el Consejo General del Poder Judicial es el órgano de gobierno del poder judicial, debería ser éste quien en materia de nombramientos tenga reconocido el derecho a elegir (y, por lo tanto, el correlativo deber de responder en caso de que su elección haya sido equivocada), en la medida en que haya que reconocerle igualmente la obligación de asegurarse de que en los órganos judiciales se encuentren los mejores jueces, los más preparados y donde se vean reflejados los distintos sectores de la sociedad.

¡Es lo que tiene desapoderar!

Cuestión distinta es saber si lo que se quiere realmente es apostar por un sistema diferente y que la magistratura española sea un conglomerado monolítico que se nutra por la estricta aplicación del escalafón, lo que a mi entender contravendría cualquier criterio de mérito, capacidad e idoneidad; esto es, si hay lugar a la discrecionalidad y, por lo tanto, si en la selección han de tenerse en cuenta otro tipo de factores o consideraciones a la hora de nominarlos o de seleccionarlos. Yo creo que sí. No todo se puede hacer depender de la antigüedad, lo que es tanto como confiar todo el destino de la justicia española a las condiciones del juez al tiempo de su ingreso en la carrera judicial ${ }^{63}$.

No existe ningún esquema patentado del principio de división de poderes que haya funcionado en todas las épocas y en todas las condiciones sociales; el verdadero sentido de la división de poderes es el de evitar la concentración del poder y con ello el posible ejercicio abusivo del mismo ${ }^{64}$. La separación de pode-

63 El juez español, siendo un juez de la legalidad, no sólo tiene que acreditar su formación jurídica en el momento de acceder a la carrera judicial sino que es su obligación mantenerla a lo largo de su vida profesional [MALEm SEÑA, J.: «La formación de los jueces: los saberes del juez», en El error judicial. La formación de los jueces, Madrid, 2009, p. 95]; del mismo autor: El error judicial y la formación de los jueces, México. 2008.

64 Bachof, O.: Jueces y Constitución, trad. Rodrigo Bercovitz Rodríguez-Cano, Madrid, 1985, p. 58. 
res no significa igualdad de poderes. La igualdad de poderes genera confrontación: la separación de poderes está pensada para que uno sirva de freno al ejercicio abusivo del poder por parte del otro poder y, en nuestro caso, el poder judicial no puede hacerse sino mediante el ejercicio de la potestad jurisdiccional ${ }^{65}$.

En muchos casos el poder judicial es el principal valedor de los principios constitucionales; quizás debido a las deficiencias de la ley, o sencillamente a causa de la inactividad de los poderes públicos, forzoso es reconocer a jueces y tribunales la facultad de suplir en ocasiones esas deficiencias o esa inactividad dispensando a los ciudadanos la tutela de sus derechos e intereses mediante soluciones integradores del ordenamiento jurídico, actuando en este sentido como verdaderos instrumentos de ordenación social ${ }^{66}$.

La calidad del poder judicial en un Estado depende en gran parte de la calidad democrática del Estado en que se inserte; de nada sirve que la Constitución proclame la independencia del poder judicial si sus integrantes no asumen cuál es su función ni los partidos políticos la suya y no respetan el papel que aquélla les ha reservado. Porque si España ha vivido por encima de sus posibilidades en materia económica, en relación con el funcionamiento de algunas de sus instituciones ha vivido, no por encima, sino en contra de sus posibilidades, pues teniendo la oportunidad de haber obrado conforme al compromiso que teóricamente debe adquirir quien asume la representación de los ciudadanos, desgraciadamente en muchos casos no lo han hecho y esto es lo que mayormente ha contribuido al descrédito de la justicia.

Ya hemos aludido al hecho de que nuestra Constitución fue el resultado de una situación; no surge con el propósito deliberado de implantar una ideología política como no fuera la de reflejar el único elemento que guio la actitud de los representantes políticos en los años de la transición: el retorno a la normalidad democrática mediante el consenso de todas las fuerzas políticas. El consenso neutralizó y difuminó cualquier intento de que una ideología se impusiera sobre las otras. Muchos años después comprobamos cómo las ideologías empiezan a hacerse ver y a manifestarse, desinhibidas ya del condicionamiento social de aquellos años, un fenómeno al que en el futuro no será ajeno el poder judicial, donde seguramente empezarán a evidenciarse las distintas formas de concebir al poder judicial y a reconsiderar su papel en el conjunto de la sociedad tanto en cuanto a su esencia como en cuanto a su existencia.

Como hemos visto, la Ley Orgánica del Poder Judicial fue, de acuerdo con el espíritu que animó a los redactores de la Constitución, el lugar donde deberían definirse estas cuestiones y donde con toda probabilidad deberían verse reflejados los valores, los principios y los ideales. Aquella ley inició una andadura con sus

$65 \mathrm{Al}$ menos esa fue la idea que subyace en la concepción que James MADISON tenía del principio de separación de poderes y que pretendió incorporar al sistema constitucional norteamericano; vid. «El federalista», cit., p. 348 .

66 Fuller, L.: «The forms and limits of adjudication», en Harvard Law Review, vol. 92, n. ${ }^{\circ}$ 2, 1978 , p. 353. 
estrategias bien definidas; desde luego incorporó preferencias y prioridades que se han materializado en las sucesivas reformas que se han llevado a cabo. Habría que saber si una ley de esta naturaleza tendría que mantenerse en los términos en que aquélla se promulgó, olvidándose de lo demás y abundando en lo principal, para que se sepa lo que es y para lo que sirve el poder judicial ante los nuevos retos que tiene que afrontar la sociedad española. No cabe duda de que cualquier ley llamada a reglamentar el poder judicial que tuviera que promulgarse ahora necesariamente tendría que ser distinta, porque sin duda distinta sería la situación a la que tendría que dar respuesta.

$Y$ hemos insistido en que los jueces no son el poder judicial sino que forman parte de él. La actividad del Estado en cuanto fuente de producción de normas se agota en el ejercicio de la función legislativa lo mismo que la función judicial se consume en el ejercicio de la potestad jurisdiccional. Y al igual que el Estado de Derecho no consentiría que el órgano encargado de crear las leyes fuera al mismo tiempo quien tuviera aplicarlas, entiendo que tampoco debería consentir que los encargados de aplicarlas fueran al mismo tiempo los responsables de crearlas. No porque pensemos que el criterio de los jueces a la hora de crearlas no fuera a ser razonable ni sensato (probablemente todo lo contrario), sino porque sus soluciones carecerían del respaldo democrático de su origen en cuanto que la norma en sí misma articula una regla de ordenación social o la respuesta política ante una determinada situación ${ }^{67}$.

Eso no quiere decir que los jueces no puedan tener ideas diferentes a las del poder político constituido ni tampoco coincidentes; sería contrario a cualquier principio democrático exigir que los jueces no pudieran tener ideas propias sobre los asuntos sobre los que ejercen jurisdicción o sobre cualquier otro que interese a la sociedad pero tanto en un caso como en otro, lo que no pueden en el ejercicio de su jurisdicción es poner sus ideas, coincidentes o no, al servicio de una causa política o ideológica: tan malo es un juez complaciente con el poder político como uno obsesiva y sistemáticamente beligerante con él.

Los jueces, como cualquiera, tienen convicciones, opiniones y preferencias; es algo inherente a la personalidad. La ideología en el juez no es incompatible con el ejercicio de su profesión; pero sí lo es cuando con ella (o a través de ella) tratan de ponerla a servicio de una causa política o influir o condicionar el resultado de la actividad jurisdiccional con ánimo de imponerla o lograr un resultado distinto de aquel que resultaría de la aplicación de los criterios legalmente establecidos ${ }^{68}$.

67 Sigue siendo útil recordar el ejemplo de la situación descrita por Edouard LAMBERT para ilustrar cómo a veces los jueces asumieron en un momento un activismo judicial negativo o involucionista respecto del programa de reformas sociales que trató de impulsar el gobierno norteamericano [El gobierno de los jueces y la lucha contra la legislación social en los Estados Unidos, edición de a cargo de Luis Pomed, trad. Félix de la Fuente, Madrid, 2010].

68 Nada mejor para ilustrar este fenómeno que el demoledor retrato del «juez político» que ha llevado a cabo Tomás y VALIENTE, alertando de los estragos que como deformación disfuncional del juez constitu- 
De ahí que hayamos de valorar el sacrificio que para muchos jueces supone en ocasiones el tener que desobedecerse a sí mismos; porque saben que cuando hablan no lo hacen por cuenta suya sino en nombre y de conformidad con lo que los ciudadanos han decidido; eso y no otra cosa es lo que sanciona el art. 117 de la Constitución al proclamar que la justicia emana del pueblo y se administra [...] por jueces y magistrados integrantes del poder judicial.

Expresar cual es la voluntad de la ley en cada caso concreto es siempre difícil; tanto, que el Estado ha decidido confiar esta actividad a un colectivo de profesionales a quienes selecciona y prepara exclusivamente con esta finalidad. Es muy posible que haya quien prefiera que no fuera así y que en la actividad judicial se redujera a un sólo acto de creación y de aplicación de la norma al caso concreto; desde luego eso ahorraría muchos costes, eliminaría la necesidad de tener una estructura judicial compleja y a lo mejor lográbamos una justicia más ágil, pero no mejor. El poder judicial es la garantía de la efectividad de los derechos y el máximo exponente del Estado de Derecho y el Derecho hace que el Estado no sea sólo el ejercicio del poder político ${ }^{69}$. Las leyes no emanan de los partidos políticos ni de los aparatos que los gobiernan, sino del parlamento, que es donde se expresa la voluntad de actuar en relación con un conflicto de intereses de una determinada manera o en un determinado sentido ${ }^{70}$. Esa es la justicia que queremos, fundamentalmente porque es el resultado del compromiso moral adquirido por quienes nos gobiernan en su afán por garantizar la dignidad de las personas ${ }^{71}$. Sabemos que otros, como los responsables de la Comisión Europea, utilizan otro tipo de criterios, y atendiendo a un principio de compensación social a la justicia la quieren para otras cosas, fundamentalmente porque consideran que una justicia eficiente mejora la actividad económica y contribuye a crear riqueza y dicen por ello que la justicia debe parecer que se hace para que mejore la economía ${ }^{72}$, lo cual no está mal, pero desgraciadamente desenfoca un poco el problema. La justicia no debe ser un instrumento concebido para crear oportunidades de negocio o garantizar operaciones comerciales sino para garantizar los derechos de los ciudadanos.

cional ha supuesto la aparición en el escenario político de nuestra historia reciente de este tipo de jueces [TOMÁs y VALIENTE, F.: «A orillas del Estado», en Obras completas, cit., p. 2.407].

69 Seguramente no compartiría esta opinión Pierre Bourdieu, que afirma que esto del Estado es cosa de juristas y togados y que es un instrumento al servicio de sus intereses; por eso dice que son partidarios del Estado porque que defendiendo al Estado lo que hacen es defender sus intereses [Bourdieu, P.: Sobre el Estado, trad. Pilar González Rodríguez, Barcelona, 2014, p. 465]. Seguramente, no sería de la misma opinión, Schmitт, C.: El valor del Estado y el significado del individuo, estudio introductorio y traducción de Celestino Pardo, Madrid, 2014, p. 13.

70 Nadie ha negado que en el ámbito de la decisión jurídica resulte fácil averiguar muchas veces esta cuestión, en la que se pueden producir errores y arbitrariedades, pero un correcto manejo de los conceptos del derecho proporciona al juez un elemento esencial para lleva a cabo su trabajo intelectual [TuHr, A.: Derecho Civil. Vol. I, trad. Tito Ravá, Madrid, 1998. p. 6].

71 Dworkin, R.: Justice for Hedgehogs, 2011, p. 329.

72 http://ec.europa.eu/justice/effective-justice/files/justice_scoreboard_2015_en.pdf. 
La actividad judicial requiere de una capacidad y de una preparación intensa de los jueces, de un apoyo logístico de envergadura y de un órgano de gobierno que genere confianza entre los ciudadanos sobre la independencia del poder judicial; también es preciso que el Estado dote a los jueces de instrumentos procesales eficaces y de una estructura organizativa que lo haga posible. Sería bueno que una nueva ley, de haberla, reforzara la esencia y en todo caso redefiniera su existencia, una existencia capaz de adaptarse a los nuevos tiempos, a los nuevos retos y a los nuevos desafíos. Esperemos que, como se ha dicho, el ansia noble de los pueblos sea capaz de alcanzar el deseo de que se haga justicia reafirmando el papel de los jueces en las sociedades democráticas ${ }^{73}$.

TITLE: What justice system do we want? Essence and Existence of the Judiciary

ABSTRACT: The author, who was a member of the Commission entrusted by the Spanish Government with drafting the Bill of Judiciary Act (2012), analyze how the judiciary has evolved to the light of the latest reforms, especially under the perspective of its body government and the elements that have contributed to the definition its fundamental features, particularly considering the influence that political parties and associations of judges have had in the independence of the Judiciary.

RESUMEN: El autor, que fue formó parte de la Comisión a quien el Consejo de Ministros encargó en 2012 que redactara una propuesta de texto articulado de Anteproyecto de Ley Orgánica del Poder Judicial, analiza cómo ha evolucionado el Poder judicial en España expuesto a la luz de últimas reformas que ha sufrido la LOPJ, especialmente desde la perspectiva, tanto la configuración constitucional de su órgano de gobierno, como los distintos elementos que han contribuido a la definición de sus rasgos fundamentales, considerando particularmente el grado de infuencia que han tenido los partidos politicos y asociaciones judiciales en la independencia del Poder judicial.

KEY wORDS: Judiciary-Judicature Act-Judiciary Body Government-Separation of powers-Rule of Law-Independence and judicial accountability.

Palabras Clave: Poder judicial-Ley Orgánica del Poder Judicial-Consejo General del Poder Judicial-Separación de Poderes-Estado de Derecho-Independencia y responsabilidad judicial.

FECHA DE RECEPCIÓN: 23.06.2015

FECHA DE ACEPTACIÓN: 29.07.2015

73 Alzaga Villaamil, O.: Comentario sistemático a la Constitución Española de 1978, cit., p. 708. 